\title{
Sobre una serie de cobres flamencos de pintores en la estela de Rubens
}

\author{
Jesús Ángel SÁnchEz RiverA \\ Universidad Complutense de Madrid, \\ Departamento de Historia del Arte II (Moderno)
}

\begin{abstract}
RESUMEN
Estudiamos una serie compuesta por ocho pinturas flamencas que se conserva en el monasterio madrileño de las Comendadoras de Santiago. Las obras, pintadas hacia 1665, conforman un ciclo completo sobre la Vida de la Virgen y se deben a cinco artistas del entorno de Rubens (1577-1640).

Damos a conocer por primera vez a dos de los pintores que intervinieron en la serie, cuyas firmas aún no habían sido descifradas; y no olvidamos poner en relación cada una de las ocho piezas con la producción conocida de sus artífices. Asimismo, con el debido apoyo documental, desvelamos la identidad de la donataria de estas pinturas al monasterio, doña Estefanía de Venegas (+ 1738), condesa de Val del Águila y religiosa profesa del mismo. Por otra parte, el estudio del conjunto permite constatar, una vez más, la repetición de ciertos modelos rubensianos por los artistas de su entorno; modelos que, junto al personal estilo del maestro de Siegen, tanta fortuna alcanzarían en la pintura barroca de nuestro país.
\end{abstract}

Palabras clave: Orden de Santiago; Monasterio de Santiago el Mayor, Madrid; Doña Estefanía Venegas, condesa de Val del Águila; Pintura flamenca; Grabado; Siglo XVII; Siglo XVIII; Anthonis Goubau I; Erasmus Quellinus II; Guillaume van Herp; Michiel Angel Immenraet; Abraham y Antoon Willensem; Peter Paul Rubens.

\section{On a series of flemish coppers in the trail of Rubens}

\begin{abstract}
We study a series made up of eight flemish paintings that is kept in the monastery of the Comendadoras of Santiago in Madrid. Are signed around 1665, and constitute a complete cycle on the Life of the Virgin. They were painted by and are owed to five artists of the environment entourage of Rubens (1577-1640). Two of the painters that intervened in the series whose signatures had not still been decoded; and we do not forget of putting in relationship to relate each of the eight pieces with the well-known production of its framers. Likewise, with the owed documentary support, reveal the identity of the donor of these paintings to the monastery, Ms. Estefanía de Venegas (+ 1738), countess of Val del Águila and professed nun in it. Furthermore, the study of the group allows to confirm, once again, the repetition of certain Rubens models by artists of its circle; models that so much fortune would reach in the Baroque paintings of our country.

Keywords: Order of Santiago; Monastery of Santiago el Mayor, Madrid; Estefanía de Venegas, countess of Val del Águila; Flemish painting; Engraving; 17th Century; 18th Century; Anthonis Goubau I; Erasmus Quellinus II; Guillaume van Herp; Michiel Angel Immenraet; Abraham and Antoon Willensem; Peter Paul Rubens.
\end{abstract}


El Real Monasterio de las Comendadoras de Santiago el Mayor de Madrid atesora una importante colección de pinturas antiguas, poco conocida y escasamente estudiada hasta la fecha ${ }^{1}$. Entre las piezas de mayor valor se encuentra una magnífica serie de ocho láminas de cobre pintadas al óleo, que componen un ciclo completo representando la Vida de la Virgen. Éste constituye uno de los conjuntos de arte mueble mejor documentados del monasterio. Todas las obras están firmadas por diferentes artistas flamencos, colaboradores o seguidores de Rubens (Quellinus, Goubau, Van Herp, Immenraet y, con ciertas dudas, Willensem)2 ; este hecho permite corroborar y establecer un buen número de filiaciones formales que analizaremos más adelante.

Sabemos que la serie perteneció a doña Estefanía de Venegas, condesa de Val del Águila y religiosa profesa del monasterio. Fue hija primogénita de don Juan de Venegas de Valenzuela (1654-1695), I conde de Val del Águila³ ${ }^{3}$ y de doña María

1 Realizamos una primera aproximación a este conjunto en nuestro trabajo de investigación de doctorado: "Aportaciones al estudio del patrimonio artístico del Convento de las Comendadoras de Santiago de Madrid", Departamento de Historia del Arte II (Moderno) de la Universidad Complutense de Madrid, 2004, pp. 79-97 (inédito). Más recientemente, nos ocupamos con mayor profundidad en nuestra tesis doctoral, titulada El Real Monasterio de las Comendadoras de Santiago el Mayor de Madrid: patrimonio históricoartístico, Madrid, Universidad Complutense, 2010, pp. 716-739 (inédita). Ambos trabajos fueron dirigidos por el Dr. D. Francisco José Portela Sandoval.

2 Las ocho láminas que componen la serie están firmadas: dos por A. Goubau (Pc-27 y Pc-28), dos por Quellinus (Pc-29 y Pc-33), dos por G. V. Herp (Pc-30 y Pc-32), una por Michiol Angel Immenraet (Pc-31) y otra lleva el anagrama "AB. (?) W." que identificamos, con las debidas reservas, con Abraham Willensem (Pc-34). Además, en tres de ellas las firmas están acompañadas por la fecha, que para todos los casos es 1665; por tanto, hemos de pensar que las no fechadas también serán de ese mismo año.

3 Don Juan Manuel de Valenzuela y Venegas había nacido en Cádiz, siendo bautizado el 26 de noviembre de 1654 en la catedral; su padrino fue don Andrés Bermúdez Carpio, canónigo penitenciario de aquella sede. Según se encargó de señalar en las pruebas para su ingreso en la Orden de Santiago, el hecho de que naciera en Cádiz fue circunstancial, y fue debido a que su padre estaba allí de paso al servicio de Su Majestad, siendo oidor del Consejo de Navarra y caballero de Santiago. Los padres de don Juan de Valenzuela fueron: don Diego Venegas de Valenzuela, natural de Córdoba y miembro del Consejo de Indias por el año 1677, y doña Inés María de Esquivel y Cerón, natural de Sevilla. Sus abuelos paternos: Juan de Venegas Valenzuela y Peregrina de Argote, naturales de Córdoba. Sus abuelos maternos: Luis de Esquivel y Constanza Cerón, o Cenni -apellido que revela una ascendencia italiana-, naturales de Sevilla.

Don Juan solicitó el hábito de la Orden santiaguista junto a su hermano Francisco (natural de Madrid), presentando las pruebas pertinentes a comienzos de 1667. Obtuvo el nombramiento el 23 de junio de aquel año. Las informaciones fueron realizadas, según era acostumbrado y preceptivo, por un caballero y por un religioso de la Orden; estos fueron don José de Fuentes y el licenciado y cura de Segura de León, don Miguel de Castro Cortés - en lugar del licenciado Alonso Guerrero de Guzmán, fallecido antes de poder comenzar la tarea-, nombrados para tal fin en mayo de 1667. A petición del pretendiente, las informaciones sobre su nacimiento se realizaron en Córdoba, ciudad de la familia paterna, y no en Cádiz. Años más tarde obtendría el cargo de corregidor de Segovia (dato que ofrece Atienza; ¿quizás quiso decir Sevilla?). También se le cita como contador de la Contaduría Mayor. El 14 de mayo de 1690 le fue concedido el título de Conde de Val del Águila, con el vizcondado previo de Pantoja. En 1693 alcanzó el cargo de asistente de la Alcaldía de Sevilla, donde murió dos años después - precisamente, este cargo ya lo habían ocupado, décadas antes, varios miembros del linaje de los Leyva, Cisneros, Cárdenas y Avellaneda, de donde procedían los fundadores del monasterio madrileño de las Comendadoras de Santiago-. Archivo Histórico Nacional [en adelante AHN], Órdenes Militares, Caballeros de Santiago, exp. 8.779 (Francisco de Valenzuela) y 8.780 (Juan de Valenzuela). También véanse ATIENZA, Julio de (barón de los Cobos de Belchite), Nobiliario español. Dic- 
Antonia del Águila y Alosa. Al parecer, doña Estefanía se casó con el gallego don Juan Alonso de Losada, a quien transmitiría el título heredado de su padre ${ }^{4}$; Losada llegó a ser nombrado miembro del Consejo de Castilla, el 20 de septiembre de 1706. Éste moriría antes que su esposa, quien, tras enviudar, tomaría la decisión de ingresar como religiosa profesa de la Orden de Santiago, a la que habían pertenecido su padre y su abuelo, entre otros familiares; el ingreso se produjo en $1720^{5}$. Al

cionario heráldico de apellidos españoles y de títulos nobiliarios, Madrid, Aguilar, 1959, p. 994; DÍAZ DE NORIEGA Y PUBUL, José, La blanca de la carne en Sevilla, Madrid, Hidalguía, 1975-1977, t. IV (1977), pp. 90 y 204-207; FAYARD, Janine, Los miembros del Consejo de Castilla (1621-1746), Madrid, Siglo Veintiuno, 1982, p. 272, n. 40 (edición original: Les membres du Conseil de Castille à l'epoque moderne, 1621-1746, Ginebra, Libraire Droz, 1979).

4 FAYARD, Janine (1982), op. cit., pp. 165, n. 77, 272, n. 33. Para saber más sobre este personaje: ibid., ad indicem.

5 Doña Estefanía Venegas de Valenzuela y del Águila, condesa de Val del Águila era natural de Madrid, según explica la genealogía presentada para su ingreso como religiosa a mediados de 1720. Entonces, su padre, don Juan Venegas de Valenzuela, era conde de Val del Águila, caballero de Santiago, miembro del Consejo de Hacienda, asistente de Su Majestad, maestre de campo general de Sevilla y veinticuatro de Córdoba. Su madre, doña María Antonia del Águila y Alosa, era natural de Madrid. Los abuelos paternos: don Diego de Valenzuela y doña Inés María de Esquivel y Cerón. Los abuelos maternos: don Juan del Águila y Eguiluz, caballero santiaguista, colegial mayor del Arzobispo de la Universidad de Salamanca y alcalde de Casa y Corte, y doña Josefa Antonia Alosa Rodarte, ambos naturales de Madrid. Además, la abuela doña Josefa era hermana de don Felipe Alosa Rodarte, caballero calatravo, secretario de Su Majestad y de la Santa Inquisición, siendo ambos hijos de Antonio Alosa Rodarte, santiaguista y secretario de Su Majestad, además del Real Patronato del Colegio de Clérigos Menores de Alcalá de Henares. En la pruebas se aducen otros nobles parentescos que legitimaron la entrada en el monasterio: el tío paterno de la aspirante, don Francisco Venegas, fue caballero de Santiago, colegial mayor de Cuenca y oidor de la Audiencia de México. El hermano del abuelo de aquélla, don Luis de Valenzuela, caballero santiaguista y veinticuatro de Córdoba. Por la parte materna, don Juan Aldrete y Carrillo, primo hermano de su abuelo, fue caballero de Santiago y familiar del Santo Oficio; los hijos de éste, don Juan y don Pedro, fueron caballero de Santiago y colegial del Arzobispo de Salamanca respectivamente. También fue primo hermano de su abuelo materno don Martín Carrillo y Aldrete, arzobispo de Granada, colegial mayor del Arzobispo e inquisidor. Otro primo hermano del abuelo, don Francisco de Eguiluz y Herencia, fue caballero de Santiago y caballerizo mayor del Infante Cardenal -ha de referirse a don Fernando de Austria, hermano de Felipe IV-; y su hijo y su nieto (don Juan y don Antonio) fueron asimismo caballeros santiaguistas.

La Comendadora Mayor del convento propuso a la pretendiente ante la comunidad, que la aceptó en votación por mayoría el 14 de junio de 1720. Doña Inés de Henao firmó como comendadora y Andrea de Larreátegui como secretaria del Capítulo. La genealogía antes referida fue aceptada el 20 de junio de 1720 por la comendadora mayor, doña Francisca Montserrat y Cruillas -acaso en el Capítulo del día 14 se le había nombrado nueva superiora del convento-, y los dos informantes santiaguistas, "Luján" y "Molinillo". Para realizar las informaciones se había de dar una fianza y 50 ducados de plata para las dietas de los informantes; quizá por ello la pretendienta solicitó -y le fue concedido- que las referentes a los abuelos maternos, naturales de Madrid, y a su padre, nacido "de paso" en Cádiz, se realizasen en Madrid, y que, de este modo, el proceso no le fuera tan gravoso. El 22 de junio el Consejo de Órdenes aprobó que se efectuasen dichas informaciones, y al día siguiente doña Estefanía abonó la cantidad referida. Finalmente, el 11 de agosto ya se había concedido la licencia de ingreso a la Comendadora Mayor y al resto de su comunidad para que ingresara la Condesa de Val del Águila, según un oficio dirigido al santiaguista don Gregorio de Tapia para que hiciera efectivo el nombramiento. AHN, Órdenes Militares, Religiosas, leg. 747.

Conocemos varios datos documentales que demuestran la unión durante el siglo XVIII del linaje de los Tapia - estrechamente vinculados a la Orden de Santiago- con el de los Montserrat y Cruillas -del que procede la Comendadora antes citada-, y asociadas ambas ramas al título de Conde de Val del Águila que venimos refiriendo. Éste es un asunto que excede las pretensiones del presente artículo, y del que aún falta por clarificar algunas cuestiones; por estos motivos lo postergaremos para un futuro trabajo. 
morir el 18 de julio de 1738, doña Estefanía dejó a la comunidad todos sus bienes, entre ellos los cuadros que analizamos, que en aquel momento se encontraban en la sacristía de la iglesia ${ }^{6}$. Es posible que las pinturas llegaran al monasterio en 1720, fecha en que ingresó la religiosa, y que acaso fueran una herencia de sus padres.

A propósito de esta hipotética herencia y de la posible adquisición de la serie por parte de la familia Venegas quisiéramos apuntar un par de cuestiones, a modo de meras conjeturas sobre el contexto en que pudieran haber sido compradas. La primera de ellas está relacionada con el gusto artístico de la Corte de Felipe IV. Bien conocida es la afición de este monarca por las artes, así como la importancia que tuvo en su colección la pintura flamenca de su tiempo. El Rey adquirió numerosas obras de los maestros flamencos del Seiscientos, con Rubens y Van Dyck a la cabeza, que fueron colgadas en el Alcázar madrileño, en El Escorial, en la Torre de la Parada o en el Palacio del Buen Retiro ${ }^{7}$. También fueron amantes de la pintura flamenca otros miembros de la Familia Real española, como la tía de aquél y gobernadora de los Países Bajos, Isabel Clara Eugenia (1566-1633), o su sucesor, y hermano del monarca, el cardenal-infante don Fernando de Austria (1609-1641). Los miembros de alta nobleza cortesana del momento, a emulación del Rey y de su familia, intentaron hacerse con obras de aquellos pintores (el Duque de Lerma, el Conde-Duque de Benavente, el Conde-Duque de Olivares, el Conde de Monterrey, el Marqués de Spínola, el Marqués de Leganés o don Luis Méndez de Haro, entre otros muchos ${ }^{8}$. Quienes no pudieron tener un original de Rubens o de Van Dyck en función de su poder adquisitivo o de sus influencias-, se conformaron con poseer copias o versiones, más o menos afortunadas, en las que, de algún modo, podrían atisbar las huellas de aquellos afamados maestros.

En segundo lugar, y no menos importante, hay que recordar la vinculación de don Diego de Venegas y de su hijo don Juan, padre de la monja santiaguista, con las ciudades de Cádiz y de Sevilla9. En Cádiz se asentó un grupo de comerciantes

6 Archivo y Biblioteca del Monasterio de las Comendadoras de Santiago de Madrid [en adelante ABCSM], "Libro de entierros de difuntas", fol. 1.

7 DÍAZ PADRÓN, Matías, Pintura flamenca del siglo XVII en España, Madrid, Universidad Complutense de Madrid, 1976 (tesis doctoral inédita), t. I, pp. 172-194.

8 Sobre los clientes españoles de Rubens, remitimos a los estudios de Alejandro Vergara.

9 Además de lo ya referido unas notas más arriba, se ha de añadir que don Diego siguió en Cádiz durante la década de 1660, trabajando al servicio de Su Majestad a través del Consejo de Indias. Sus tareas estuvieron ligadas al control comercial de mercancías en el puerto, comisionado por dicho Consejo, del que más tarde fue miembro (1677). Al parecer, tenía el cargo de alcalde -de Sevilla (?)- (doc. entre 1660 y 1662), aunque residiera el Cádiz. En mayo de 1662 debía de encontrarse enfermo, pues solicitó al Consejo su marcha de la ciudad por esta causa. Hubo de fallecer entre 1667 y 1668, porque en agosto de este último año su viuda, doña Inés María de Esquivel, solicitó al Consejo los gajes que disfrutaba su marido, así como una casa de aposento y una encomienda de indios vacos, peticiones que fueron otorgadas por aquel organismo. Vid. HEREDIA HERRERA, Antonia (dir.), Catálogo de las consultas del Consejo de Indias, Sevilla, Diputación Provincial de Sevilla, 1983-1995, t. X (1993) y XI (1994), ad indicem (Diego Venegas de Valenzuela, Diego Venegas y Juan Venegas). 
flamencos encargados de importar pinturas provenientes de su tierra de origen ${ }^{10}$, de manera que se generó un fecundo comercio de obras artísticas que compraban no sólo los nobles, sino también el clero y comerciantes adinerados ${ }^{11}$. Entre las cartas e inventarios del marchante Matthijs Musson, establecido en Amberes, se consignan numerosos envíos de pinturas al puerto de Cádiz, en especial durante la década de 1660; y sabemos que el pintor Abraham Willensem, quien parece firmar una de las obras de las Comendadoras, figura entre los artífices que enviaron obras a través de Musson. Precisamente por los años en que están fechados los cobres que estudiamos, Musson envió a Cádiz distintos lotes de pinturas para sus clientes españoles, como don Alonso, alcalde mayor de la ciudad, don Diego Carvajal (ambos en 1665) y don Juan Gómez de Castrillo (en 1666) ${ }^{12}$. También podemos citar una de las sociedades más conocidas, la de los Forchondt, aunque se estableciese cinco o seis años después de la serie que estudiamos -lo que no es óbice para que las obras se pudieran vender unos años más tarde de su ejecución-. Tanto Justo como Alexandre y Guillaume Forchondt II (1640-h. 1711), pintor del que se conocen varias obras ${ }^{13}$, se asentaron en el próspero enclave andaluz para importar y exportar mercancías, probablemente asociados con su padre, residente en Amberes, al menos durante los primeros años ${ }^{14}$. Forchondt "el Joven" había sido discípulo de Erasmus Quellinus II, y, además, importó obras de Van Herp, dos de los artistas que intervinieron en la serie que estudiamos ${ }^{15}$. Igualmente, en la ciudad de Sevilla existió un fecundo comercio de pintura flamenca, monopolizado por la importante colonia que existía de oriundos de aquellas tierras septentrionales de Europa. Todo parece indicar que la importación de productos de dichas latitudes hubo de ser un lucrativo negocio. Al parecer, los Forchondt también tuvieron casa comercial en la ciudad del Guadalquivir ${ }^{16}$; y la firma de estos pintores-marchantes exportaba también a Málaga ${ }^{17}$. Además tenían una sucursal en Viena, donde había trabajado el padre de la saga, a cargo de sus hijos Alexandre y Guillaume ${ }^{18}$. La ciudad de Sevilla

10 DÍAZ PADRÓN, Matías (1976), op. cit., t. I, pp. 19 y 112.

11 Ibid., t. I, p. 242.

12 Ibid., t. I, p. 222. El estudio de referencia, que cita este autor, es el publicado por DENUCÉ, Jan, $N a$ Peter Paul Rubens, documenten uit den Kunsthandel te Antwerpen in de XVII Eeuw Van Matthijs Musson, Amberes, 1949, en especial pp. 159, 255, 268 y 329.

13 Están identificadas varias obras suyas en España, entre ellas, curiosamente, dos pinturas con la Aparición de Santiago en la batalla de Clavijo (Museo Provincial de Valencia y colección privada de Madrid), DÍAZ PADRÓN, Matías (1976), op. cit., t. IV, pp. 1339-1344. Otras pinturas, junto a su semblanza, aparecen en FERNÁNDEZ PARDO, Fernando (coord.), Pintura Flamenca Barroca (Cobres, siglo XVII), catálogo de la exposición (1997), San Sebastián, 1996, pp. 226-232. Recientemente salió un cobre de la Asunción en el mercado madrileño que podría asignarse a este pintor, obra que repetía esquemas rubensianos; $c f r$. Catálogo de Durán Subastas (Madrid), noviembre 2010, lote nº 19 (se le cita como Guillermo Forchen).

14 El pintor Guillaume I, documentado desde 1632 y muerto en 1678.

15 DÍAZ PADRÓN, Matías (1976), op. cit., t. I, pp. 113 y 367.

16 Ibid., t. I, p. 113.

17 Ibid., t. I, p. 367.

18 Ibid., t. I, p. 368. 
era el lugar donde se había establecido don Juan Venegas de Valenzuela, quien ocupó diversos cargos de importancia, llegando a alcanzar el cargo de asistente de la ciudad en 1693 hasta su muerte, en $1695^{19}$. Otros miembros de su familia tuvieron una posición preeminente en Sevilla, y hemos de pensar que no serían ajenos -más bien todo lo contrario- a su ambiente artístico y comercial.

Pocos años debieron de estar los cobres en la antigua sacristía construida por los hermanos Manuel y José del Olmo, pues unas décadas después se derribaría para levantar la actual sacristía de los Caballeros (entre 1745 y 1753), el majestuoso espacio diseñado por Francisco de Moradillo. Por otra parte, son muy numerosos los ejemplos conocidos de este tipo de series flamencas en el interior de las sacristías españolas, como acertadamente señaló el profesor Valdivieso ${ }^{20}$. Todo indica que hubo de estar de moda dentro del ámbito eclesiástico el adornar estos espacios con dichas pinturas.

La serie completa fue fotografiada en la sacristía por el estudio de Moreno años antes de la Guerra Civil española ${ }^{21}$. Pocos años después fue incautada por el Gobierno republicano durante el conflicto armado, trasladándose al depósito del Museo del Prado para su protección. Acabada ya la Guerra, fue devuelta a las religiosas el 12 de abril de 1940 por el Servicio de Defensa del Patrimonio Artístico Nacional $^{22}$. De este momento se conservan fotografías de cada una de las obras ${ }^{23}$.

El primero que dio noticia de la serie fue Tormo, aunque sólo citó los "cobres pintados (de la serie de siete)" que pudo ver en la antesacristía ${ }^{24}$; con esta vaga descripción hemos de pensar que el historiador no debió ver uno de ellos y, además, no pudo leer las firmas. Medio siglo más tarde sería Matías Díaz Padrón quien ofreciera más información, dando la autoría de algunas de las piezas y estableciendo agudas observaciones en relación a la obra de cada uno de sus artífices, aunque también introdujera ciertos errores ${ }^{25}$. Este autor menciona varias de ellas

19 El de asistente podría equipararse al puesto de corregidor, siendo la máxima autoridad municipal; presidía el Cabildo de la ciudad. Vid. DÍAZ DE NORIEGA Y PUBUL, José (1975-1977), op. cit., t. IV, p. 52 y ss.

20 VALDIVIESO, Enrique, “Obras inéditas de Willem van Herp”, en Boletín del Seminario de Estudios de Arte y Arqueología, XXXIX, 1973, p. 483.

${ }^{21}$ Los negativos actualmente se conservan en el Instituto del Patrimonio Cultural Español [en adelante IPCE], Archivo Moreno [en adelante AM], 2708/A, 2709/A, 2710/A, 2711/A, 2712/A, 2713/A, 2715/A y 2718/A.

22 Archivo Central del IPCE, Servicio de Defensa del Patrimonio Artístico Nacional [en adelante SDPAN], sig. 130.40, recibo $\mathrm{n}^{\circ} 958, \mathrm{n}^{\circ}$ de orden 1-8. Es muy probable que los marcos de todas ellas, en su reverso, conserven las etiquetas de la Junta de Incautación -aunque no lo hemos podido comprobar personalmente-, cuya numeración está recogida en el recibo del SDPAN.

23 IPCE, Archivo Arbaiza [en adelante AA], MP-8809, MP-8810, MP-8811, MP-8812, MP-8813, MP-8814, MP-8815 y MP-8816.

24 TORMO, Elías, Las iglesias del antiguo Madrid, 2 fascículos, Madrid, Imprenta de A. Mazo, 1927, § 38 (en la reedición de: Madrid, Instituto de España, 1979, p. 172).

25 DÍAZ PADRÓN, Matías (1976), op. cit., vol. VII, p. 2382, ad indicem (Comendadoras de Santiago). Este autor atribuye las piezas a Pierre van Lint (1609-1690), Van Herp, Goubau y Quellinus, aunque, como explicaremos, el primero nada tuvo que ver en ella; y las obras debidas a Goubau tampoco se comentan. Ibid., vol. IV, p. 1397. 
en diversos artículos referidos a dichos pintores ${ }^{26}$. El Inventario publicado en 1983 los citaba ${ }^{27}$; sin embargo, no recogió las firmas ni las fechas -seguramente, por desconocimiento de lo publicado por Díaz Padrón-. También ciertas piezas han sido expuestas al público fuera del monasterio; las fichas de cada una de ellas se encuentran en los catálogos correspondientes, aunque no añaden nada a lo aportado por aquel especialista ${ }^{28}$. Por nuestra parte, ya estudiamos la serie en relación con las fuentes impresas que influyeron en varias de sus composiciones ${ }^{29}$.

El estado de conservación de las piezas es excepcional, aunque han sido sometidas a diversas intervenciones ${ }^{30}$. Afortunadamente, también han mantenido sus antiguos marcos, cuya tipología "de rizo" fue muy frecuente y característica de los Países Bajos durante el siglo XVII; de hecho, se conocen también como "flammenleisten" $"$.

Los ocho cobres que conforman la serie son los siguientes ${ }^{32}$ :

\section{Nacimiento de la Virgen [Pc-27] (fig. 1)}

La escena se desarrolla en un interior de gran amplitud. En primer término la Virgen recién nacida es lavada por tres mujeres, y otras tres que se apresuran a ayudar; más allá, Santa Ana permanece en la cama, recuperándose de su parto, atendida por una mujer que le lleva unas sopas; al fondo se ve a otra secando ropa junto a la chimenea; en la zona superior hay un rompimiento de gloria con la paloma espiritual y ángeles que portan una filacteria donde se lee el nombre de la protagonista que abre esta serie de pinturas: "S. MARIA".

26 Están referidos a lo largo de las notas, por lo que ahora los omitimos.

27 TOVAR MARTÍN, Virginia (dir.), Inventario artístico de edificios religiosos madrileños de los siglos XVII y XVIII, t. I, Madrid, Centro Nacional de Información Artística, Arqueológica y Etnológica, 1983, pp. 123 y 125.

${ }^{28}$ Catálogo de la Exposición Conmemorativa del Primer Centenario de la Diócesis Madrid-Alcalá, catálogo de la exposición (Madrid, 1986), Madrid, Caja de Ahorros y Monte de Piedad de Madrid, 1986, pp. 340-343; Santa María, Madre de Dios. 800 años de devoción a la Santísima Virgen en los conventos de las Madres Comendadoras de Santiago, catálogo de la exposición (Granada, noviembre-diciembre 2004), Granada, MM. Comendadoras de Santiago - Cofradía de la Oración de Nuestro Señor en el Huerto de los Olivos y María Stma. de la Amargura, 2004, p. 16.

29 SÁNCHEZ RIVERA, Jesús Ángel (2004), op. cit., pp. 79-92; SÁNCHEZ RIVERA, Jesús Ángel, "Fuentes grabadas de las pinturas del Convento de Santiago el Mayor de Madrid. Aproximación a su estudio", en XVI Congreso Nacional de Historia del Arte. La Multiculturalidad en las Artes y en la Arquitectura, t. II, Las Palmas de Gran Canaria, Anroart, 2006, pp. 702, 704-705.

${ }^{30}$ La más reciente, finalizada en 2008, se llevó a cabo en el taller de Carmen Enrile Corsini y estuvo financiada por Caja Duero.

31 TIMÓN TIEMBLO, María Pía, El marco en España. Del mundo romano al inicio del Modernismo, Madrid, Publicaciones Europeas de Arte, 2002, pp. 82-83 y 257-259.

32 En nuestra tesis doctoral ofrecemos alguna información más de carácter técnico sobre cada una de las piezas, además de recoger la mayor parte de su bibliografía; SÁNCHEZ RIVERA, Jesús Ángel (2010), op. cit., pp. 726-739, fichas Pc-27 - Pc-34. Junto al título de cada obra incluimos, entre corchetes, la signatura que fijamos en aquel estudio para cada una de ellas. 


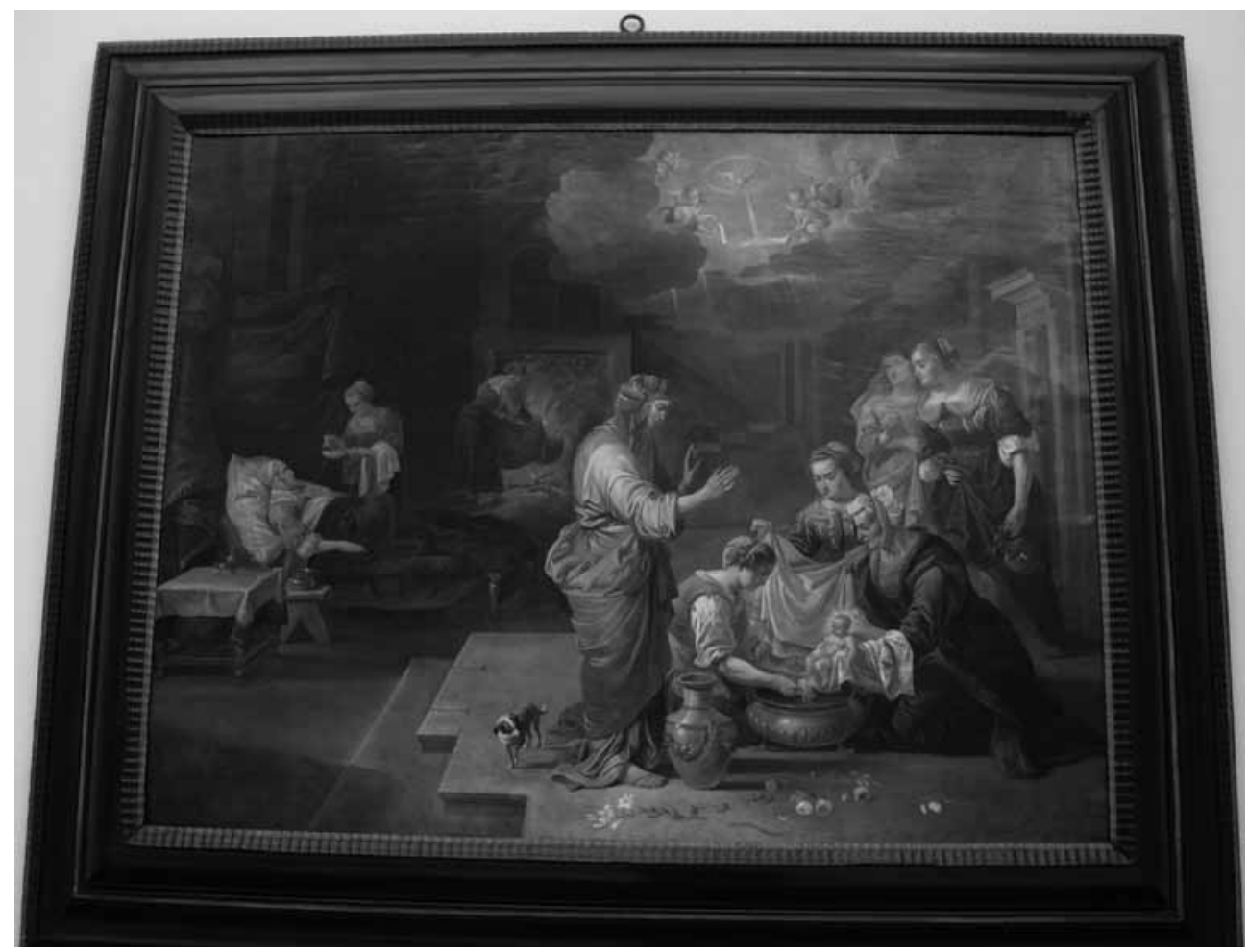

Fig. 1. Anthonis Goubau I, Nacimiento de la Virgen, ca. 1665, óleo sobre cobre, 121 x 146 cm. (marco original), Madrid, monasterio de las Comendadoras de Santiago, Pc-27.

Como es sabido, todos los episodios de la juventud de la Virgen María están inspirados en los Evangelios apócrifos, pues en los canónicos sólo se menciona a María estando ya casada. Para la representación de la Natividad de la Virgen los artistas copiaron las fórmulas utilizadas para el Nacimiento de Cristo; en esta pintura el nombre de María en la filacteria ayudaría a evitar confusiones entre ambos asuntos.

Está firmada por Anthonis (o Anton, o Antonio) Goubau I (1616-1698) ${ }^{33}$, pintor nacido en Ámsterdam formado con Juan de Farins -o Johannes de Farius- (doc. entre 1622 y 1623 en la Guilda de San Lucas de Amberes), que alcanzó la maestría en 1636, y que en 1655 ingresó en la Compañía de Jesús en Malinas. También firmó la Virgen, San Joaquín y Santa Ana (Pc-28), dentro del mismo ciclo. Como ya hemos avanzado, las ocho láminas que componen la serie llevan el nombre autógrafo de su autor correspondiente. En tres de ellas las firmas están acompañadas por la fecha ${ }^{34}$, que para todos los casos es 1665; por tanto, consideramos que las no fechadas, como ésta, serán de ese mismo año.

33 Firmado en el ángulo inferior derecho: “A. Goubau. F”, [“Anthonis Goubau Fecit”].

34 Las signadas como Pc-29, Pc-31 y Pc-33, realizadas por Quellinus e Immenraet. 
Los cinco artistas hubieron de repartirse el trabajo de este encargo, algo bastante frecuente en estas series flamencas. Cinco pintores que fueron permeables en mayor o menor medida a la pintura de Rubens, según iremos viendo. En este sentido, Goubau es quien parece acusar menor influencia de los cuatro.

Hay en esta pintura el gusto por el detalle, e incluso por lo anecdótico, que caracteriza a la pintura flamenca: la representación menuda de los objetos (los jarros y la bañera, las flores y el perro, la mesita con frutas, cuchillo, copa y jarra, o el bacín), los detalles como dar la caldo a la recién parida -la costumbre de dar este reconstituyente también fue común en España- o secar la ropa a la lumbre. Por otro lado, varios de estos elementos entrañan además cierto simbolismo, como las flores (rosas, lirios), asociadas a María, o las tablas de los Diez Mandamientos -con caracteres pseudo-hebraicos- que presiden la chimenea, aludiendo a la Antigua Ley frente a la Nueva Ley que se anuncia con el nacimiento de la madre de Cristo.

También se puede señalar el intento por parte del pintor de introducir elementos de carácter "arqueológico", como la bañera y los jarros "romanos" que usan las parteras, y tal vez la figura femenina que está de pie en primer término. Quizá haya que recordar que Goubau viajó a Italia, donde pudo perfeccionar su arte, si bien la presencia de elementos de la Antigüedad romana e italianizantes fue bastante común en determinados círculos del arte flamenco.

\section{La Virgen niña con San Joaquín y Santa Ana [Pc-28] (fig. 2)}

Como el cobre anterior, está firmado sin fecha por Anthonis Goubau (1616$1698)^{35}$. En primer término aparece la Virgen niña entre San Joaquín y Santa Ana. Sobre ellos se abre el cielo, surgiendo el Espíritu Santo en forma de paloma, y ésta rodeada de ángeles, algunos con instrumentos musicales de cuerda y de viento. En segundo término, a ambos lados del grupo central, hay dos escenas: a nuestra izquierda un pastor cuidando de su rebaño (ovejas, cabras y un perro); a la derecha, Joaquín tiene la visión de un ángel, que le entrega un lienzo con una inscripción, probablemente pseudo-hebraica. Toda la representación acontece en un paisaje abierto que se pierde en la lejanía.

Esta representación se fundamenta en los Evangelios apócrifos ${ }^{36}$. Al pastor Joaquín, tras años de matrimonio con Ana, se le apareció en el campo un ángel del Señor anunciándole que sería padre de una niña que sería bendita y "madre de eterna bendición" ${ }^{37}$. Es precisamente lo que aparece en segundo término a la derecha;

${ }^{35}$ Firma la parte inferior izquierda: "A. Goubau. F", [“Anthonis Goubau Fecit"].

${ }_{36}$ Concretamente, en el Protoevangelio de Santiago, IV, 2, en el Pseudo Mateo, III, 1-3, o en el De nativitate Mariae, III, 1-4.

${ }^{37}$ Pseudo Mateo, III, 2. Citamos por la edición de Los Evangelios Apócrifos, Madrid, Biblioteca de Autores Cristianos, 1996, p. 183 ( $9^{\mathrm{a}}$ edición; $1^{\mathrm{a}}$ edición: Madrid, BAC, 1956; colección de textos griegos y latinos, versión crítica, estudios introductorios y comentarios de Aurelio de Santos Otero). 


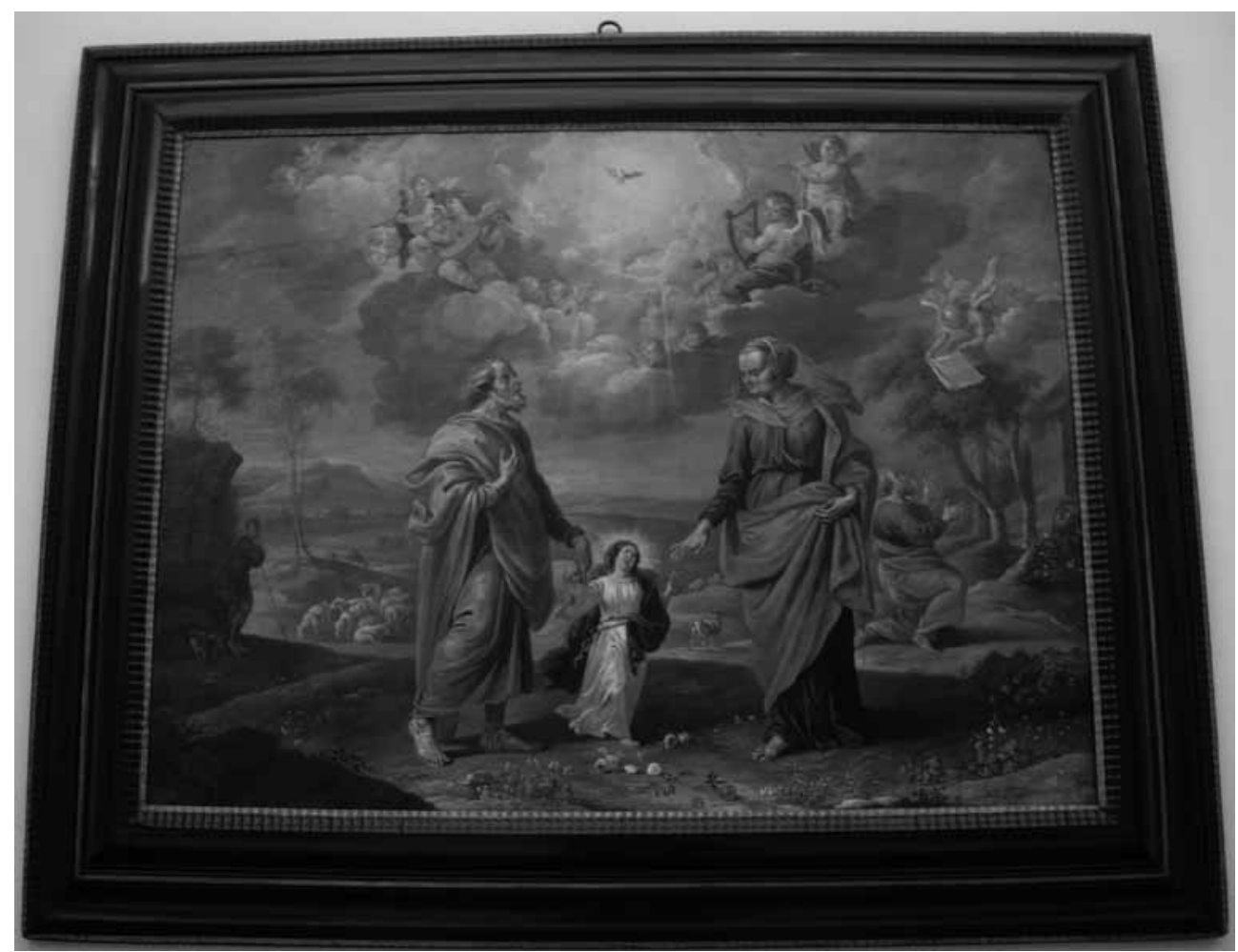

Fig. 2. Anthonis Goubau I, La Virgen niña con San Joaquín y Santa Ana, ca. 1665, óleo sobre cobre, 121 x $146 \mathrm{~cm}$. (marco original), Madrid, monasterio de las Comendadoras de Santiago, Pc-28.

pensamos que el pastor que cuida del rebaño es uno de los criados de Joaquín, ajeno a la visión de su amo. En primer término aparece Joaquín, Ana y su hija María, confirmación de la profecía divina; y Joaquín mira significativamente al cielo, que se abre apareciendo la paloma espiritual, irradiando luz entre el grupo angélico. Este último episodio no es narrado por los textos evangélicos; se ha de buscar su origen en la tradición iconográfica occidental. Al presentar los dos momentos narrativos en una misma escena (el anuncio a Joaquín y el llamado "Destino de la Virgen") se pretendería señalar el sentido profético del nacimiento de María, futura madre del Mesías.

Subyace aquí una composición bastante simétrica, a diferencia de la anterior, donde la estructura espacial se articulaba a través de diagonales. En el presente cobre, el grupo principal se alinea ordenadamente en el centro, en eje con el círculo de nubes; y se dejan en segundo plano las dos escenas secundarias que se cierran a su vez por dos estructuras arquitectónicas. No obstante, ciertos recursos empleados por Goubau en las dos obras son semejantes, como el rompimiento de gloria en la zona superior o las flores del suelo - esta vez acompañadas por plantas silvestres-, que, aparte de su consabida carga simbólica, animan la escena. 
Quizá lo más atractivo de esta pieza sea su gran riqueza y brillantez cromática, pues las figuras no están muy logradas -por ejemplo, Santa Ana- y resulta excesivamente simétrica, como ya se ha dicho. Respecto a la factura, vale lo mismo que el anterior: gran detallismo en los elementos más menudos, con pequeños y finos toques de pincel (flores, plantas), o el trabajo de ciertas zonas con pinceladas más largas (vestiduras) o más gruesas y trabadas (celajes, pasto).

\section{Anunciación [Pc-29] (fig. 3)}

El tercer cobre de la serie legada por la condesa de Val del Águila lo firma Erasmus Quellinus II (1607-1678) ${ }^{38}$. Además, está fechado en 1665, como la Adoración de los Reyes Magos (Pc-31) y Jesús entre los doctores del Templo (Pc-33) -el último también de este artista-, lo que nos permite datar el momento de realización de la serie completa. Quellinus, hijo de un pintor homónimo, de quien recibiría su primera formación, fue discípulo de Rubens, sucediendo a éste tras su muerte en 1640 como pintor oficial en Amberes. En 1635 había participado junto al maestro de Siegen en la decoración de la Torre de la Parada; e, igualmente, ayudó al maestro en distintos proyectos para grabar sus composiciones más celebradas. También copió obras de Van Dyck, pintor al que admiró y del que poseyó alguna pintura ${ }^{39}$.

La presencia de este autor en España es bastante significativa ${ }^{40}$. Según acabamos de referir, fue uno de los artistas que enviaron pinturas para la decoración de la Torre de la Parada; éstas representan asuntos mitológicos dentro de un complejo programa iconográfico mucho más amplio, y hoy se encuentran en el Museo del Prado ${ }^{41}$. Pero, al margen de los encargos regios, algunas pinturas hubieron de venir por otras vías para satisfacer la demanda de obras de devoción de gentes pertenecientes al clero, la nobleza y otras personas adineradas, como testimonian estos cobres. Otro cuadro de asunto religioso atribuido con seguridad a Quellinus y conservado en España es un lienzo de la Virgen con Jesús Niño y San Juanito perteneciente al Museo Lázaro Galdiano ${ }^{42}$.

La composición que ahora nos ocupa guarda cierta relación con otra pintura de una colección madrileña, ésta sobre lienzo, que dio a conocer Matías Díaz Padrón hace un par de décadas. En su estudio, este autor ya señaló las semejanzas con el

${ }^{38}$ Firma y fecha en el ángulo inferior izquierdo: "Quellinus invent. et fec. A. 1665”, ["Quellinus invenit et fecit. Annus 1665].

${ }^{39}$ DE BRUYN, Jean-Pierre, Erasmus II Quellinus (1607-1678). De Schilderijen met catalogue raisonné, 4, Düsseldorf, Luca Verlag Freren, 1988.

40 Vid. DÍAZ PADRÓN, Matías (1976), op. cit., t. II, pp. 640-656.

${ }^{41}$ El rapto de Europa $\left(\mathrm{n}^{\circ} 1.628\right)$, Baco y Ariadna ( $\left.{ }^{\circ} 1.629\right)$, La muerte de Eurídice $\left(\mathrm{n}^{\circ} 1.630\right)$, Jasón con el vellocino de oro $\left(\mathrm{n}^{\circ} 1.631\right)$, Cupido navegando sobre un delfin $\left(\mathrm{n}^{\circ} 1.632\right)$, Las arpías perseguidas por Zetes $y$ Calais $\left(\mathrm{n}^{\circ} 1.633\right)$, Psiquis y el Amor dormido $\left(\mathrm{n}^{\circ} 1.718\right)$.

${ }_{42} \mathrm{~N}^{\circ}$ 8.061. Al parecer, sin embargo, procede de la colección parisina del español. 


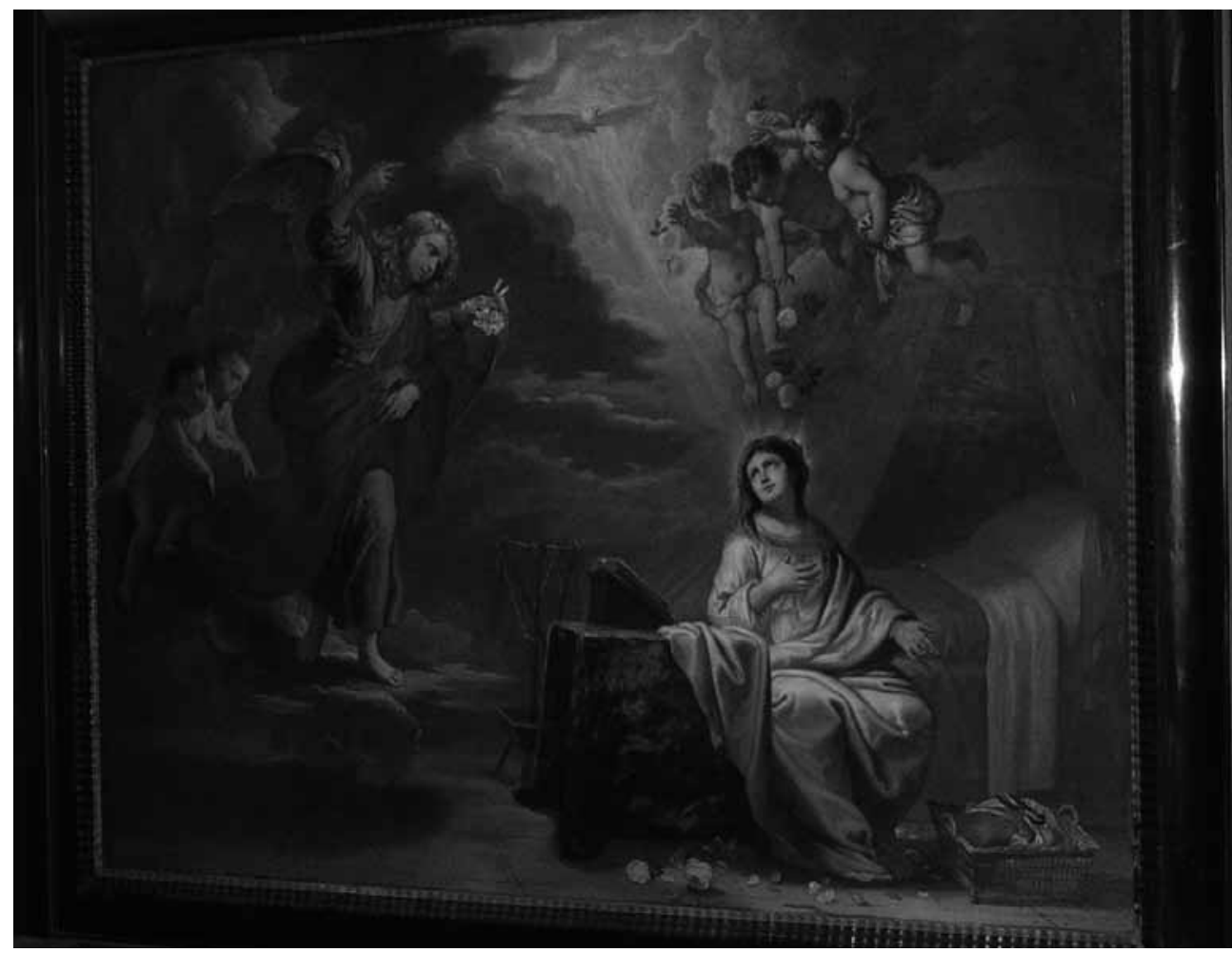

Fig. 3. Erasmus Quellinus II, Anunciación, 1665, óleo sobre cobre, 121 x $146 \mathrm{~cm}$. (marco original), Madrid, monasterio de las Comendadoras de Santiago, Pc-29.

cobre de las Comendadoras, a la vez que establecía otras comparativas con obras del propio Quellinus y de Rubens ${ }^{43}$.

El misterio de la Encarnación, también designado como la Anunciación, se basa en el Evangelio de San Lucas (1,26-38) y el los Evangelios apócrifos de la Natividad anteriormente citados; infinitas veces representado en la tradición iconográfica cristiana, sus fórmulas son bien conocidas. La Virgen está rodeada de los objetos que refieren los relatos apócrifos: el huso y el cesto de costura, una mesa con las Sagradas Escrituras, también la cama-con su toldo a la moda flamenca- ${ }^{44}$. Gabriel, con un ramo de azucenas y acompañado por dos ángeles, le transmite su mensaje

43 DÍAZ PADRÓN, Matías, "Une Annonciation inédite de Jan Erasmus Quellinus à Madrid", en Koninklijk Museum voor Schone Kunsten de Amberes, Jaarboek, 1990, pp. 295-301.

44 Este mueble aparece en otras pinturas de su mano, como en un Nacimiento de la Virgen que fue adquirido hace unos años por el Estado con destino al Museo del Prado; Maestros del Barroco europeo, catálogo de la exposición (Madrid, 2005), Madrid, Coll \& Cortés Fine Art Dealers, 2005, pp. 114-115, nº cat. 34 (ficha de José Juan Preciado). También aparece en el catálogo razonado escrito por DE BRUYN, Jean-Pierre (1988), op. cit., pp. 223-224, $\mathrm{n}^{\circ} 172$. 
indicando la venida del Espíritu Santo en forma de paloma. María acepta su papel, y tres angelotes le lanzan rosas desde las alturas. Casi toda la estancia se inunda de nubes, a través de las cuales se abre paso una luz dorada y la paloma espiritual.

Quellinus se muestra como un pintor más diestro que Goubau. Sus figuras son más bellas y elegantes -se advierte en ello la influencia de Van Dyck-, y sus expresiones y ademanes están mucho más logrados; son también de canon más corto, mejor proporcionadas. Es de alabar, además, la representación de las diversas calidades materiales de los objetos. El trabajo de luces y sombras es muy notable. El cuadro tiene la brillantez cromática habitual en este tipo de cobres flamencos, y todo está realizado con gran minuciosidad, advirtiendo un trabajo algo más suelto para los tejidos, con trazos largos y precisos.

Según la inscripción autógrafa, la composición se debe al propio Quellinus.

\section{Visitación de la Virgen a Santa Isabel [Pc-30] (fig. 4)}

El amberino Guillaume van Herp (1614-1677) firma la Visitación ${ }^{45}$. Como veremos, Van Herp hace uso de esquemas compositivos rubensianos en las dos obras que firma de la serie, pero la factura, el dibujo y el color, incluso muchos de los tipos humanos, son en todo suyos, siendo quizá el artista más personal de los que intervienen en ella.

Se han publicado numerosos cobres de este pintor en iglesias, conventos y colecciones españolas ${ }^{46}$, aparte de las que guardan algunos de nuestros museos ${ }^{47}$. De este modo, encontramos cobres suyos pertenecientes al Museo del Prado, aunque la mayoría están depositados en diferentes museos provinciales; entre otros se cuentan: la Huida a Egipto ( $\left.\mathrm{n}^{\circ} 1.720\right)$, las Bodas de Caná $\left(\mathrm{n}^{\circ} 1.722\right)$, la Consigna de la Iglesia ( $\mathrm{n}^{\mathrm{o}}$ 1.724), o un Bautismo de Cristo ( $\left.\mathrm{n}^{\mathrm{o}} 2.291-\mathrm{P}\right)$. En el convento del Henar (Segovia) hay dos sobre la vida de San Antonio. En la catedral de Granada se le atribuyen otros tres, dentro de una serie más amplia sobre la vida de Cristo. En la catedral de Segovia hay uno. Y otro en la iglesia parroquial de Navalcarnero (Madrid). Diversas obras se conocen en colecciones privadas: en Madrid un lienzo de Isaac bendiciendo a Jacob; el Diluvio Universal (col. Rodríguez López); Daniel en el foso de los leones (col. Quesada) y el Rapto de Elías; Nacimiento de la Virgen (col. Ruiz); Nolli me tangere; en San Sebastián un cobre con el Sueño de San José; en Sevilla un asunto de la Bilocación de San Antonio; y en Las Palmas de Gran Canaria dos lienzos, la Batalla de Clavijo y la Prisión de Francisco I en Pavía (col.

${ }^{45}$ Firma en el ángulo inferior izquierdo: "G. V. HERP”, [“GUILLAUME VAN HERP”].

${ }^{46}$ Matías Díaz Padrón apuntó que "su obra no llega a España por la vía noble de la Corte, sino por la Iglesia y el pueblo devoto"; DÍAZ PADRÓN, Matías, "Un cobre de Willem van Herp con El sueño del Patricio Juan y su esposa del templo de la Virgen de las Nieves", en Archivo Español de Arte, LXXVI, nº 301, 2003, p. 85 .

${ }^{47}$ DÍAZ PADRÓN, Matías (1976), op. cit., ad indicem, en especial vol. IV, pp. 1387-1415. 


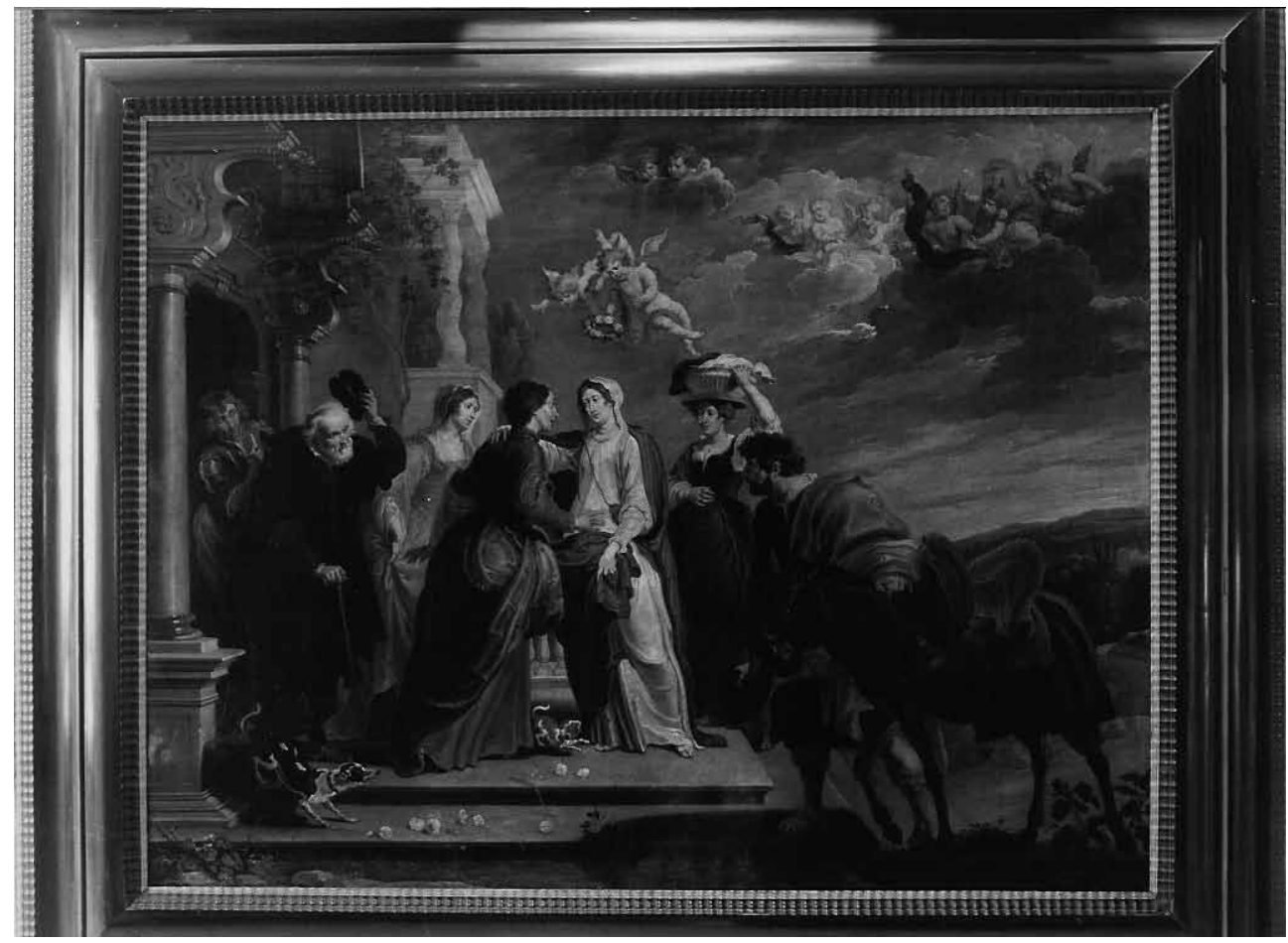

Fig. 4. Guillaume van Herp, Visitación de la Virgen a Santa Isabel, ca. 1665, óleo sobre cobre, 121 x $146 \mathrm{~cm}$. (marco original), Madrid, monasterio de las Comendadoras de Santiago, Pc-30.

Manr); Van Herp colaboró, además, en la serie histórica de don Guillermo Raymond de Moncada, hoy repartida entre distintos herederos de la familia. Asimismo, a las tierras hispanoamericanas llegaron obras de Van Herp, como una Anunciación o El sueño del patricio Juan y su esposa de colección mexicana ${ }^{48}$.

A esta larga lista se pueden añadir otras muchas piezas documentadas, y más atribuciones, que no citamos por no extendernos en exceso ${ }^{49}$. Si damos cuenta de todas estas obras, principalmente de asuntos religiosos, es para insistir en la destacada presencia de este artista en nuestro país, satisfaciendo a una clientela muy concreta.

48 Remitimos a los trabajos de VALDIVIESO, Enrique (1973), art. cit., pp. 483-488; DÍAZ PADRÓN, Matías, Museo del Prado. Catálogo de Pinturas, I: Escuela Flamenca. Siglo XVII, 2 vols., Madrid, Museo del Prado, 1975, pp. 155-157, láms. 109-111; DÍAZ PADRÓN, Matías, "Obras de Guillaume van Herp en España. I", en Archivo Español de Arte, L, no 200, 1977, pp. 361-382; DÍAZ PADRÓN, Matías, "Obras de Guillaume van Herp en España. II”, en Archivo Español de Arte, LI, n 201, 1978, pp. 1-27; DÍAZ PADRÓN, Matías, "Nuevas pinturas de Guillaume van Herp", en Miscelánea de Arte, Madrid, CSIC, 1982, pp. 168-173; DÍAZ PADRÓN, Matías, "Nuevas pinturas de satélites de Rubens inéditas o mal atribuidas, en colecciones españolas y extranjeras: Van Lint, Van Herp, Th. W. Bosschaert y Van Balen”, en Archivo Español de Arte, $\mathrm{n}^{\circ}$ 241, 1988, pp. 1-11; DÍAZ PADRÓN, Matías (2003), art. cit., pp. 83-88.

49 Díaz Padrón es quien más se ha ocupado de este asunto, y a sus trabajos remitimos; vid. supra. 
Es muy frecuente encontrarle trabajando junto a otros pintores en la realización de series en cobre para su exportación, de modo semejante a la que ahora nos ocupa.

En lo que nos concierne, particularmente interesante es la existencia de algunas réplicas de esta composición de la Visitación realizadas por el propio Van Herp (en colección particular de Madrid, y otra vendida en la sede londinense de Christie`s), y de las numerosas copias, recogidas todas por Díaz Padrón ${ }^{50}$. La enorme proliferación de ejemplares autógrafos y copias testimonia la fortuna alcanzada por esta composición; en relación con ello, Díaz Padrón se hace eco de una noticia del marchante Musson, quien envió a Málaga varias copias de Rubens en 1663 -muy cercanas a las piezas fechadas que estudiamos, de 1665-, entre ellas una Visitación de Van Herp ${ }^{51}$. Este autor, al hablar de la Visitación de la colección privada madrileña, señala que: "sólo se diferencia de la primera réplica en la falta de flores en las escaleras del pórtico". No advierte, sin embargo, que la presencia de las flores en la obra de las Comendadoras responde a una concepción común del ciclo mariano, pues en seis de los ocho cobres aparecen estos símbolos. Hecho que pondría de manifiesto la estrecha colaboración de los pintores en dicho trabajo.

Isabel recibe la visita de la Virgen María a la puerta de su casa (San Lucas, 1, 39-45). Las acompañan sus dos esposos, Zacarías y José; también dos mujeres, que se suelen reconocer como las hermanas maternas de la Virgen, María Cleofás y María Salomé; y un joven imberbe, probablemente un criado de la casa. La presencia de todos estos personajes no se recoge en el relato bíblico, pero cuenta con una larga tradición iconográfica. El acontecimiento extraordinario de ambos embarazos se subraya con la presencia celestial de un grupo de ángeles, dos de los cuales coronan a María con flores. Animan la composición dos perros y el burro que lleva San José de las riendas; además, en el suelo aparecen flores -alusivas a María, como en casi todos los cuadros de la serie- y otras plantas menudas. A la izquierda, una arquitectura evoca la casa de Zacarías -mezcla de elementos clásicos y fantásticos, y columnas salomónicas al fondo-; y al lado contrario aparece un paisaje con amplio espacio destinado al celaje.

Es notable la captación de gestos y actitudes de los personajes (por ejemplo, Zacarías y su joven acompañante), así como el trabajo de sus atuendos. Todo realizado con una factura sumamente precisa, minuciosa y de gran viveza. Además de la evidente impronta de Rubens, tal vez pueden advertirse ciertos ecos de la pintura de Van Dyck; en la gama de tonos fríos (azulados, grises, violáceos) usada por el

50 DÍAZ PADRÓN, Matías (1976), op. cit., vol. IV, pp. 1394-1395 y 1397, así como otras reproducciones antiguas que han salido al mercado internacional, algunas de ellas de pobre calidad: Christie`s de Londres, 6-X-1950; Net. Int. de la Haya, n ${ }^{\circ}$ 7274; Christie`s de Londres 27-II-1948, lote $n^{\circ} 38$ (subastada de nuevo en Sotheby`s de Ámsterdam el 10 de mayo de 2005, lote n 5, como obra de Van Herp); Galería Lepke, Berlín, 22-XI-1921, no 116; Galería Rosenberg de Berlín, 24-XI-1922, nº 55. Véase también DÍAZ PADRÓN, Matías (1977), art. cit., p. 375.

${ }^{51}$ DÍAZ PADRÓN, Matías (1976), op. cit., t. IV, p. 1395. 
pintor, y, quizás también, en cierta elegancia que respiran las figuras. Tampoco se ha de desdeñar la posible influencia de Quellinus, copartícipe en la serie, y del que Van Herp copió alguna composición ${ }^{52}$. Aunque, por encima de todo, prevalece el particular estilo de Van Herp.

Díaz Padrón señaló acertadamente la inspiración en el grabado de Pieter de Jode (1606-h. 1674), según el lateral izquierdo del tríptico que Rubens realizara para la catedral de Amberes, si bien Van Herp lo adapta al formato apaisado -añadiendo más figuras, entre otros cambios-, y lo reinterpreta a su manera ${ }^{53}$. En el otro cobre que firma de la serie (Pc-32) sigue el panel de la derecha a través de otra estampa, según veremos.

\section{Adoración de los Reyes Magos [Pc-31] (fig. 5)}

Esta Adoración de los Reyes Magos reproduce fielmente una composición homónima de Rubens, bien a través de la obra original, conservada en el Musée des Beaux-Arts de Lyon, bien a través de alguna de las copias estampadas en sentido inverso del grabado realizado por Lucas Vosterman I (1595-1675) en 1621 de aquella obra ${ }^{54}$.

La Adoración ideada por el maestro de Siegen hubo de ser muy popular en nuestra tierra. Pérez Sánchez ya dio a conocer numerosas pinturas españolas inspiradas en dicha composición rubensiana, con mayor o menor grado de fidelidad ${ }^{55}$. A éstas podemos añadir dos piezas más pertenecientes al Museo del Prado: una catalogada como obra flamenca del siglo XVIII (en depósito en el Museo de Málaga) y otra catalogada como de Francisco Rizi (en depósito en la Universidad de Barcelona). O también la Epifanía del retablo mayor de la iglesia parroquial de Pinto (Madrid), o la de las Capuchinas de Madrid, ambas de Antonio de Pereda. Según se puede apreciar, esta composición difundida a través de estampas tuvo un gran éxito entre los artistas españoles, que adaptaron el modelo foráneo a sus propias capacidades y sensibilidades. Y, en relación con este extremo, la obra que ahora presentamos es la que sigue más fielmente el original, sin lugar a dudas por una mayor asimilación de los modelos y los modos de Rubens por parte de sus coetáneos flamencos.

52 DÍAZ PADRÓN, Matías (1978), art. cit., p. 15.

${ }_{53}$ DÍAZ PADRÓN, Matías (1977), art. cit., pp. 363, 371 y 375.

${ }^{54}$ HOLLSTEIN, Friedrich Wilhelm H., Dutch and flemish etchings, engravings and woodcuts, ca. 14501700, Ámsterdam, Menno Hertzberger (primeros volúmenes), 1949-2007, 71 vols. (serie compilada por F. W. H. Hollstein hasta su muerte, en 1957, y continuada hasta 2007), vol. XLIII (1993), pp. 18-19, nº 9, copias: b (firmada por "CIVisscher"), c, d, e, f (de Jacob Wangner).

55 Dos pinturas de Mateo Gilarte (conservadas en la iglesia de Santo Domingo de Mula, Murcia, y en el Museo de Gerona); una de José Mateos (Museo de Murcia, depósito del Museo del Prado); una de Pedro Camacho Felices (iglesia colegial de San Patricio, en Lorca); una en la catedral de Plasencia; y otras cuatro en diferentes colecciones privadas (una en Barcelona, una en Sevilla y dos en Madrid). PÉREZ SÁNCHEZ, Alfonso Emilio, "Rubens y la pintura barroca española", en Goya, no 140-141, 1977, pp. 98-101. 


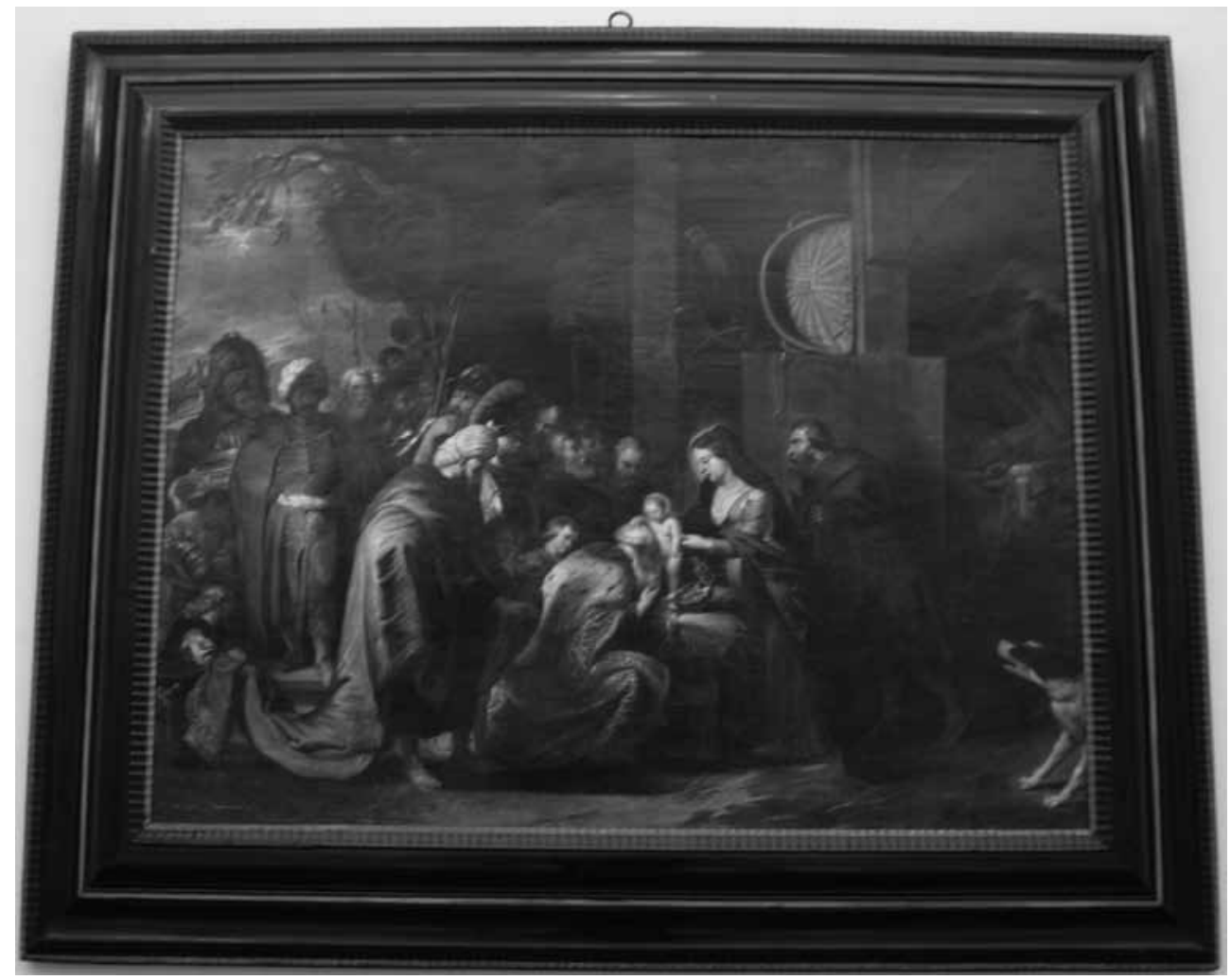

Fig. 5. Michiel Angel Immenraet, Adoración de los Reyes Magos, 1665, óleo sobre cobre, 121 x $146 \mathrm{~cm}$. (marco original), Madrid, monasterio de las Comendadoras de Santiago, Pc-31.

La pieza está firmada en la zona inferior. Puede leerse claramente el nombre compuesto del pintor, Michiol -o Michel- Angel; más complicado es leer el apellido, que, sin duda, hemos descifrado como "Immenraet"56. La utilización de composiciones de Rubens por parte de este pintor flamenco poco conocido debió de ser frecuente; por ejemplo, Díaz Padrón cita una que representa el Triunfo de David (en 1930 estaba en la colección Von Nickl, Budapest), según un grabado de Jan van Saeredan -o Saenredam- (1565-1607) ${ }^{57}$.

La Epifanía, asunto de sobra conocido y representado, tiene por fuentes literarias al Evangelio de San Mateo (2, 1-12) y el relato de algunos Evangelios apócrifos. Esta representación añade un gran número de personajes a los estrictamente necesarios (la Sagrada Familia y los tres Magos); dieciocho personas forman parte del séquito de los Reyes; además aparecen animales (el buey que recogen las fuentes literarias, un perro o un par de caballos). La suntuosidad de los atuendos y

\footnotetext{
56 Firmado y fechado en el ángulo inferior izquierdo: "Michiol Angel Immenraet fecit. 1665".

57 DÍAZ PADRÓN, Matías (1976), op. cit., vol. IV, p. 1652.
} 
regalos de los Reyes y de su comitiva contrasta con la humildad y el realismo del establo y de sus huéspedes. La escena queda dividida verticalmente en dos por un muro, desarrollándose entre el interior y el exterior desde donde llega la comitiva. En el centro, en eje con dicho muro, queda la figura del Niño Jesús, que acaricia con ternura la cabeza de Melchor.

El cromatismo general de este cobre es más oscuro y terroso que el de las pinturas precedentes, en gran medida por estar ambientado su mayor parte en el interior del establo. También el contraste lumínico es más acusado. El trabajo con el pincel es exquisito y minucioso, con gran atención sobre la representación fidedigna de los objetos (telas, regalos, armaduras, lanzas, aperos, madera, etc.); muy notables son, asimismo, los rostros y sus expresiones.

Llama la atención el que no sea citado por Díaz Padrón, al igual que la Asunción (Pc-34), quien sí menciona los otros seis cobres. De este modo, presentamos esta pieza como prácticamente inédita, pues sólo la nombra el Inventario de 1983, con las consabidas carencias informativas.

\section{Presentación de Jesús en el Templo [Pc-32] (fig. 6)}

La Presentación de Jesús en el Templo es un episodio más de este ciclo mariano, pues además puede entenderse como la Purificación de la Virgen. El anciano Simeón sostiene al Niño en sus brazos, a punto de entregárselo a su madre, mientras acontece la revelación divina -representada por cabezas angelicales entre nubes- que relata el Evangelio ${ }^{58}$. Dos hombres maduros y una anciana, la profetisa Ana, acompañan al anciano; y otros dos jóvenes acólitos portan grandes antorchas, según la liturgia católica. San José permanece arrodillado ante Simeón, haciendo entrega de las dos palomas que exigía el ritual de purificación judío en el caso de los pobres. Detrás, un grupo de mujeres contempla la escena; una de ellas, con un niño en los brazos, muestra su seno. Todo se desarrolla en un amplio escenario arquitectónico de carácter clásico. Y, de nuevo, aparecen las flores alusivas a María esparcidas por el suelo.

El mismo autor de la Visitación (Pc-30), Guillaume van Herp, firma esta obra ${ }^{59}$. Como en la anterior, adapta a su manera una composición ajena, aunque en la Presentación la deuda con la estampa es mayor. Pero los modelos, así como la fina factura y el colorido, responden a su particular estilo. La sensualidad, riqueza y brillantez cromática es de gran belleza (contiene múltiples tonos de apariencia esmaltada: rojos, rosas, azules, verdes, amarillos, blancos, grises).

Para esta composición Van Herp se inspiró directamente en una estampa de Paulus Pontius (1603-1658) que versiona el panel derecho del tríptico de la catedral de Amberes de Rubens; es muy significativo que para la otra lámina que firmó el pin-

\footnotetext{
58 Lucas, 2, 28-31.

59 Firma en el ángulo inferior derecho: “G.: V. HERP”, [“GUILLAUME VAN HERP”].
} 


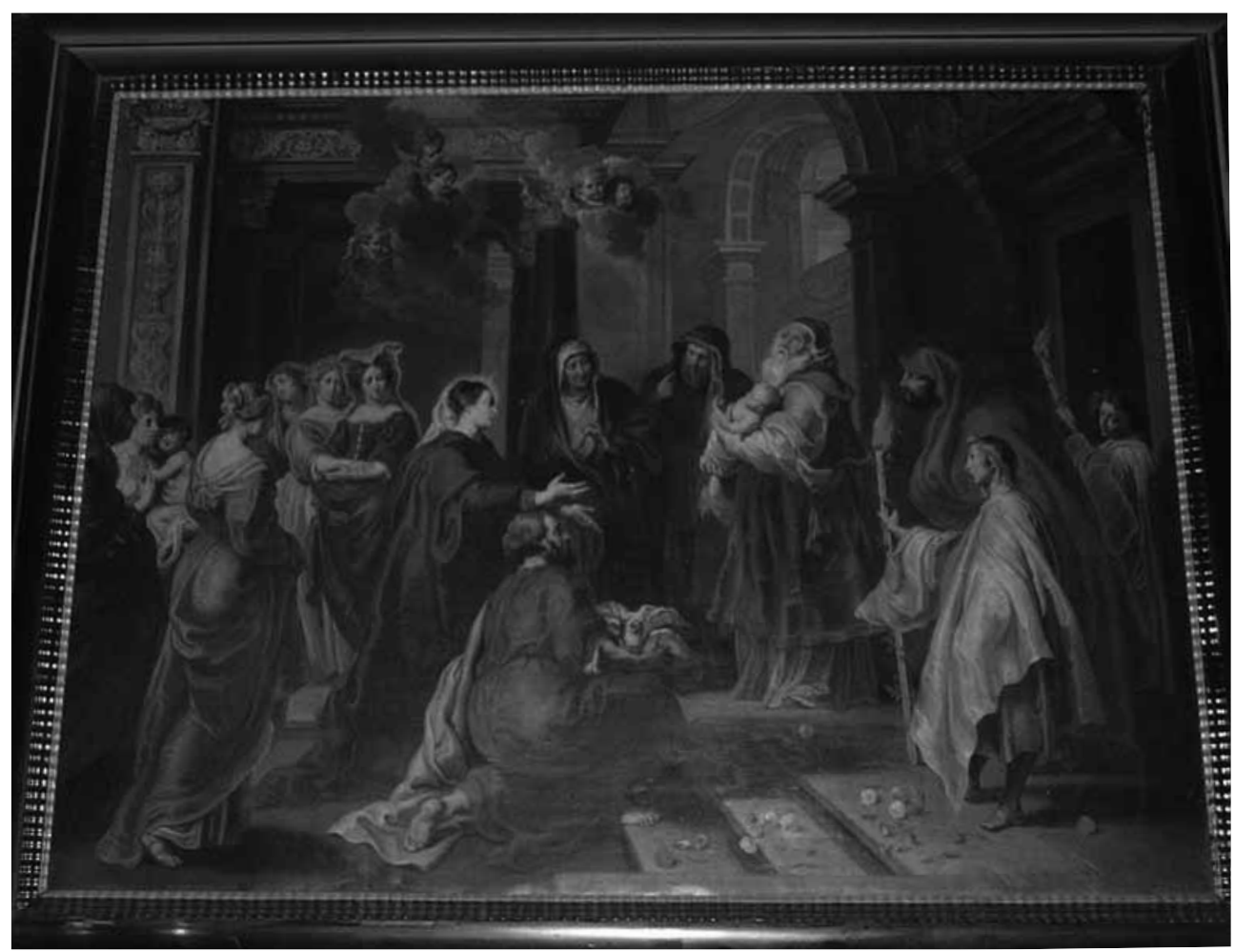

Fig. 6. Guillaume van Herp, Presentación de Jesús en el Templo, ca. 1665, óleo sobre cobre, 121 x 146 cm. (marco original), Madrid, monasterio de las Comendadoras de Santiago, Pc-32.

tor tuviera en mente el panel de la izquierda, también a través de una estampa. Pero al adaptarse al formato apaisado de la serie, Van Herp amplió la escena, añadiendo seis figuras más (cuatro mujeres, un hombre y un joven) y el grupo angélico, que no aparecían en el grabado. Esta modificación la resuelve el pintor con gran maestría, pues otorga mayor espacio y suntuosidad a la composición original. Todo lo contrario sucede con la versión sobre lienzo del murciano Senén Vila (iglesia de San Andrés, Murcia), que también amplía horizontalmente el espacio, pero pintando el mismo número de figuras que el grabado, todo interpretado de modo austero y sin gracia $^{60}$. La composición rubensiana sería repetida en otras ocasiones por los artistas hispanos, siempre a través de imágenes impresas, como en las pinturas murales del coro del monasterio toledano de San Clemente.

60 PÉREZ SÁNCHEZ, Alfonso Emilio (1977), art. cit., pp. 90-91. 


\section{Jesús entre los doctores del Templo [Pc-33] (fig. 7)}

Es el segundo cobre firmado por Quellinus, e igualmente está fechado 1665. Su firma revela que la composición se debe a la invención del propio artífice, frente a los cobres signados como Pc-30, Pc-31, Pc-32 y Pc-34, inspirados en estampas ${ }^{61}$. El primer cuadro del artista (Pc-29) también luce un orgulloso "invenit" tras su apellido.

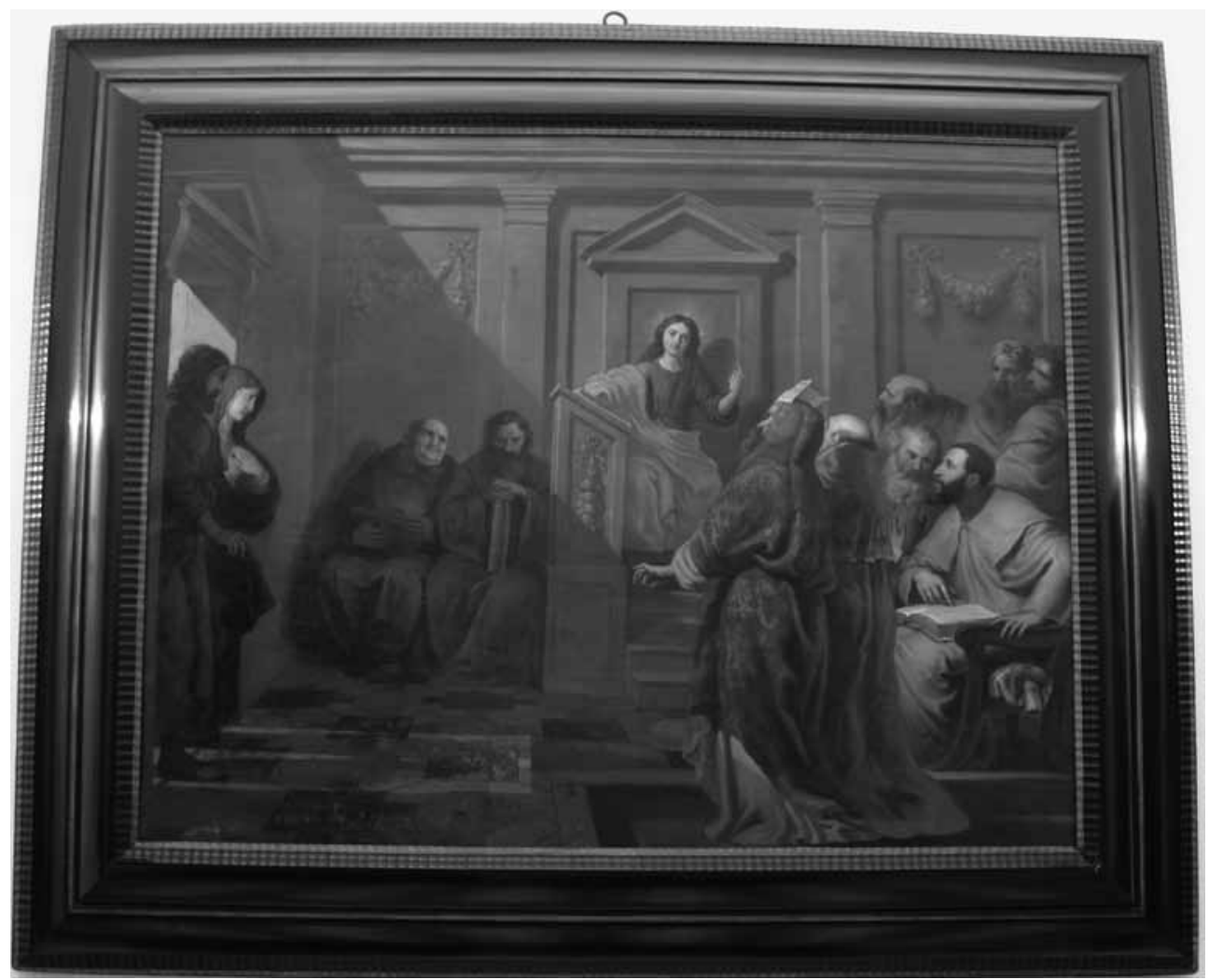

Fig. 7. Erasmus Quellinus II, Jesús entre los doctores del Templo, 1665, óleo sobre cobre, 121 x $146 \mathrm{~cm}$. (marco original), Madrid, monasterio de las Comendadoras de Santiago, Pc-33.

El asunto representado es el de la presencia de Jesús, aún niño, entre los doctores del Templo de Jerusalén (recogido por San Lucas, 2, 41-50, y por ciertos relatos apócrifos), pero dentro de este ciclo de la vida de María debe interpretarse también como uno de los Siete Dolores de la Virgen; de este modo enlaza con la profecía

${ }^{61}$ Firma y fecha en el ángulo inferior izquierdo: “Quellinus inven. et fec. A. 1665”, [“Quellinus invenit et fecit. Annus 1665']. 
de Simeón durante su purificación en el Templo, escena que precede a ésta y que dice así: "Éste [Jesús] está destinado para caída y elevación de muchos en Israel, y como signo de contradicción - ¡a ti misma [María] una espada te atravesará el alma!- (...)"62. Jesús preside el templo ex cathedra, y transmite su enseñanza entre los doctores. Los sabios muestran diferentes actitudes ante sus palabras: escuchan sorprendidos, pensativos, discuten entre ellos. Entran por la puerta José y María, que, según los evangelios, llevaban tres días buscando a Jesús; María se lleva las manos al corazón, con un gesto mezcla de alivio y dolor.

Quellinus ofrece un amplio repertorio de tipos humanos entre los doctores: unos vestidos al modo judío (incluso con escritura hebrea en el manto de uno o en un rollo de la Thorá sobre la frente de otro); otros como sabios de la Antigüedad clásica; otro luce un turbante al modo oriental; y el orondo personaje sentado al extremo izquierdo podría pasar por un moderno fraile. Esta variedad es lo más destacable del cuadro, cuya suciedad y oscurecimiento impide apreciar sus calidades cromáticas de manera adecuada. La figura de la Virgen no está a la altura del resto -adviértase, por ejemplo, la incorrección en el dibujo de sus manos-. El Templo de Jerusalén sirve al pintor para representar una arquitectura clásica de gran severidad, donde iluminación procedente del exterior crea fuertes contrastes de luces y sombras, subrayando los elementos constructivos y decorativos. El suelo se resuelve con un embaldosado de diseños geométricos que termina por armar la estructura espacial donde se insertan las figuras.

\section{Asunción de la Virgen [Pc-34] (fig. 8)}

Diversas obras del anagramista A. W. del Museo del Prado fueron atribuidas al pintor Arthour Wolfort (1581-1641), autoría que ya fue rechazada desde hace tiempo por Díaz Padrón ${ }^{63}$, quien se las asignó a Antoon Willensem. Valdivieso ${ }^{64}$, por el contrario, asignó ciertas pinturas firmadas con estas iniciales a Abraham Willensem (h. 1610-1672), quien llegó a ser decano del gremio de pintores de Amberes y tuvo gran relación con los Forchondt. Para el caso que ahora nos ocupa, la atribución de Valdivieso parece la más probable, puesto que la lectura que hacemos de la firma sería "AB. [enlazadas, ?] W. F." ${ }^{65}$. No obstante, mantenemos ciertas reservas por

${ }^{62}$ Lucas, 2, 34-35. Citamos por la Biblia de Jerusalén, Barcelona, Desclée De Brouwer, 2006, p. 1495 (traducción de la edición francesa de: París, Éditions du Cerf, 1998).

63 Para las obras conservadas en España que llevan este anagrama, vid. DÍAZ PADRÓN, Matías (1976), op. cit., vol. IV, pp. 1634-1644; algunas de ellas forman series (sacristía de la catedral de Almería; convento de Carmelitas Descalzas de Alba de Tormes; santuario de El Henar, Segovia). Véase también DÍAZ PADRÓN, Matías y PADRÓN MÉRIDA, Aída, El siglo de Rubens en el Museo del Prado. Catálogo razonado de pintura flamenca del siglo XVII, Madrid, Prensa Ibérica, 1995, t. II (Abraham Willemsen y Anagramista A. W.).

${ }^{64}$ VALDIVIESO, Enrique, "Dos pinturas de Abraham Willemsem en el Museo del Prado y otras obras de este pintor en España”, en Boletín del Museo del Prado, VII, n 21, 1986, pp. 166-172.

65 Firmado en la zona inferior, en el borde del escalón. 


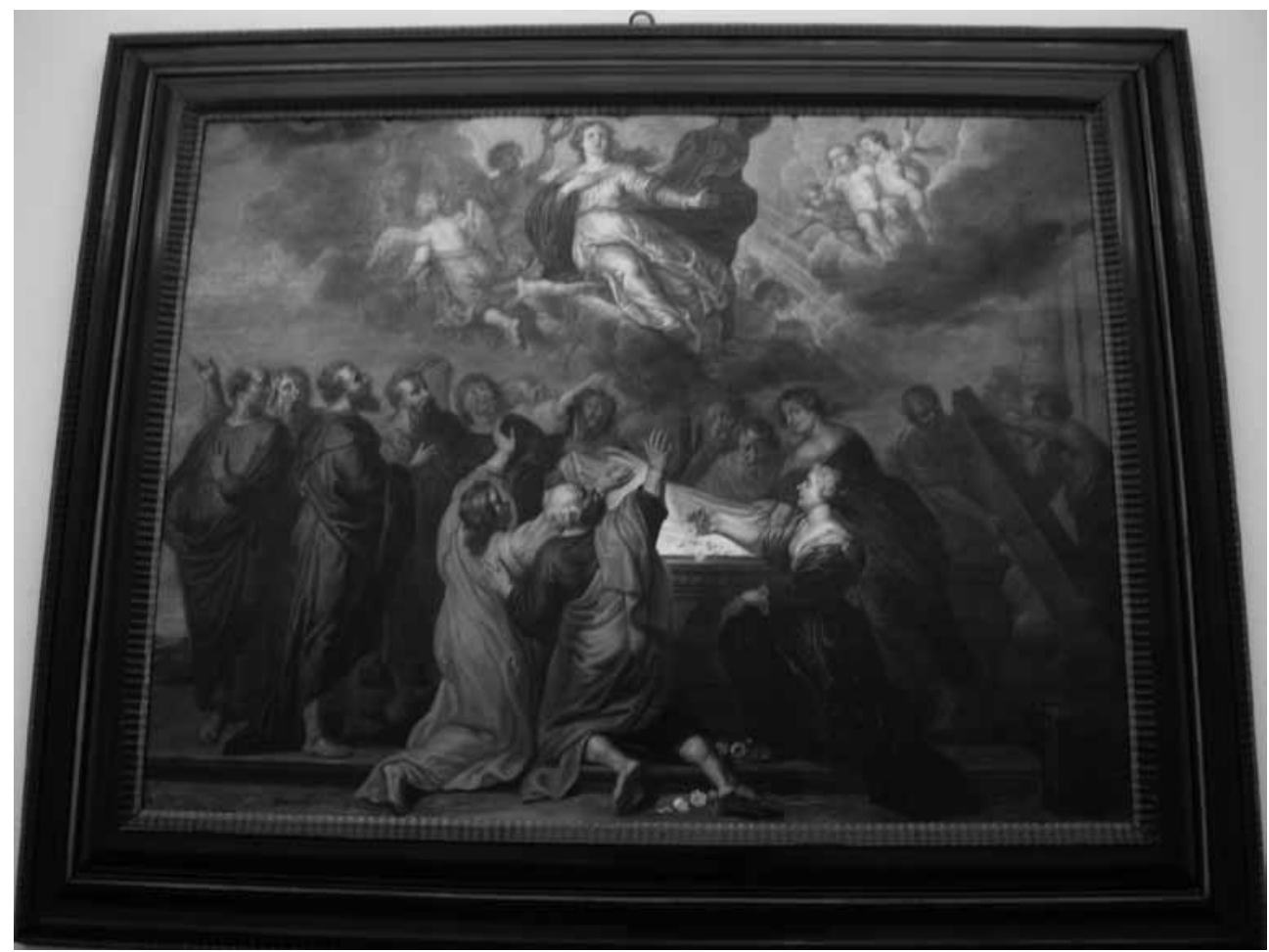

Fig. 8. Abraham o Antoon Willensem (?), Asunción de la Virgen, ca. 1665, óleo sobre cobre, 121 x $146 \mathrm{~cm}$. (marco original), Madrid, monasterio de las Comendadoras de Santiago, Pc-34.

su lectura dificultosa y por no conocer lo suficiente la obra de ambos artífices. En cualquier caso, el primer pintor citado, Wolfort, queda totalmente descartado por haber fallecido mucho tiempo antes de la ejecución de esta serie.

Representa la Asunción de la Virgen a los cielos, rodeada de ángeles, asunto que, como es sabido, no aparece en las Escrituras -deriva de una tradición legendaria-. En el plano inferior están el colegio apostólico y las tres Marías, junto al sepulcro vacío de la Virgen; muestran gestos y actitudes diversas ante el insólito acontecimiento al que asisten. Dos varones retiran la lápida; el resto aparece de pie, a modo de friso, salvo San Juan y San Pedro, que figuran arrodillados ante el sepulcro vacío. Una de las Santas Mujeres, también arrodillada, recoge algunas flores de la tumba; según la leyenda, se hallaron flores en lugar de María -un motivo que se repite en los cobres precedentes-. Las otras dos mujeres se mezclan entre el apostolado.

La composición deriva parcialmente de una obra de Rubens, hoy en el Kunstmuseum de Düsseldorf, grabada en 1624 por Paulus Pontius, previa corrección del pintor. Nuestro artista tomó literalmente el grupo de la Virgen y su acompañamiento angélico, y al utilizar el formato apaisado que exigía el encargo, eliminó la figura 
de Cristo que hay en la composición original -cuyo formato es vertical-. Sin embargo, el grupo de la parte inferior parece más directamente inspirado en otra composición rubensiana de la Asunción que se conserva en la Colección Liechtenstein de Vaduz ${ }^{66}$. Añadiremos que hay un libro en el suelo, trasunto de los que aparecen en la escena grabada por Pontius; pero en el extremo derecho se vislumbra parte de una arquitectura que no aparece en el original.

Díaz Padrón dio a conocer una pintura de la Asunción firmada con el anagrama A. W. F. (colección Maiz Zulueta, Madrid) que tendría una composición similar: de formato apaisado e inspirada en la referida invención de Rubens ${ }^{67}$. Lamentablemente, no conocemos la pieza, ni siquiera por fotografía, y por ello no podemos establecer vínculos con la obra de las Comendadoras, aunque sospechamos que ambas pudieran deberse al mismo pintor.

En España conocemos un cobre flamenco publicado hace unos años que copia la pintura conservada en Düsseldorf de modo completo, incluso imitando el formato $^{68}$. Por otra parte, Pérez Sánchez ya señaló en su día dos lienzos españoles que tenían la misma fuente de inspiración, aun con notables variaciones compositivas ${ }^{69}$.

El presente cobre es el que presenta un tratamiento mucho más barroco, en correspondencia con el original rubensiano. Las figuras tienen mayor vigor y movimiento, y su asombro se traduce en variedad de gestos y expresiones. El trabajo con el pincel es preciso, y de cierta soltura, sobre todo en el tratamiento de cabellos, barbas y telas. Aunque está bastante sucia, se puede apreciar una gran variedad de tonos: ocres, blancos, verdes, azules, grises, rojizos, rosáceos... Una limpieza sacaría a la luz toda su brillantez.

La Asunción de las Comendadoras viene a constatar una vez más la enorme fortuna y difusión que alcanzó la obra del prolífico artista de Siegen, tanto en su propio entorno como en el mundo hispánico.

${ }^{66}$ Cfr. Corpus rubenianum, 24 vols. (en publicación), Bruselas, Arcade Press; Harvey Miller-Heyden \& Son, 1967- (edición escrita por varios autores de la obra iniciada por Ludwig BURCHARD en la primera mitad del siglo XX, que no vio publicada), Part. VII. The life of Christ after the Passion (1984), pp. 163-169, $184-188, \mathrm{n}^{\circ}$ cat. 41 y 44.

67 Al parecer, es de un tamaño algo menor que el de las Comendadoras $(85$ x 67 cm.). DÍAZ PADRÓN, Matías (1976), op. cit., vol. IV, pp. 1638-1639.

68 Cfr. FERNÁNDEZ PARDO, Fernando (coord.) (1996), op. cit., p. 210.

69 PÉREZ SÁNCHEZ, Alfonso Emilio (1977), art. cit., pp. 101-102. 